\title{
CALAGEM, ADUBAÇÃO E NUTRIÇÃO MINERAL DE ANONÁCEAS ${ }^{1}$
}

\author{
DANILO EDUARDO ROZANE ${ }^{2} \&$ WILLIAM NATALE ${ }^{3}$
}

RESUMO- Entre os fatores edáficos, os ligados à acidez são os que mais interferem na produtividade, especialmente nas regiões tropicais. Para a cultura das anonáceas, não há resultados de pesquisa que indiquem a adequada saturação por bases, nem tão pouco a determinação de doses, épocas, modos de aplicação e fontes de nutrientes para pomares de anonáceas em formação e produção, a fim de promover sustentabilidade e elevadas produtividades. Tendo em vista a importância e o potencial de exploração comercial das anonáceas no Brasil e, considerando-se a escassa informação científica disponível sobre calagem, adubação e nutrição dessa família de plantas frutíferas, algumas pesquisas têm urgência de serem realizadas em função dos efeitos dos nutrientes sobre a produtividade, a qualidade dos frutos, a pós-colheita, a tolerância a pragas e doenças e, etc.

Termos para indexação: Annona spp., calcário, acidez do solo, adubo, nutrição de plantas.

\section{LIMING, FERTILIZER AND MINERAL NUTRITION OF ANNONACEAE}

ABSTRACT: Among the edaphic factors, those related to acidity are the ones that affect productivity, especially in tropical regions. For culture the Annonaceae, no research results that indicate the proper base saturation, nor the determination of doses, times, application methods and sources of nutrients for orchards Annonaceae in training and production in order to promote sustainability and higher yields. Given the importance and potential of commercial exploitation of Annonaceae in Brazil and, considering the limited available scientific information on liming, fertilization and nutrition of fruit plants of this family, some research has to be carried out urgently due to the effects of nutrients on productivity, fruit quality, postharvest, tolerance to pests and diseases, etc.

Index terms: Annona spp., lime, soil acidity, fetilizer, plant nutrition.

\section{INTRODUÇÃO}

A grande ordem Magnoliales abrange a família Annonaceae e a subfamília Annonoideae que compreende inúmeros gêneros, dentre os quais se destacam a Annona, Rollinia e a Aberonoa que contemplam mais de 2.000 espécies (SOUZA; LORENZI, 2005), sendo as de maior importância comercial a Graviola (Annona muricata); a Pinha, Fruta-do-conde ou Ata (Annona squamosa); a Cherimólia (Annona cherimolia), e a Atemoia, um hibrido, resultante do cruzamento da Annona squamosa e da Annona cherimolia.

As anonáceas têm seu centro de origem na região tropical, embora existam algumas espécies de clima subtropical (DONADIO, 1997) e temperado (SILVA; SILVA, 1997). Dentre os principais produtores mundiais, destacam-se os Estados Unidos, a Índia, a Espanha, o México, o Chile, a Venezuela e o Brasil (DONADIO, 1997).
Embora não haja dados estatísticos sobre a área cultivada e a produção de anonáceas no Brasil, é crescente a demanda pela polpa da fruta, a fim de suprir os mercados interno e externo. Isso tem motivado os fruticultores, pois se sabe que a maior parte da produção é proveniente de pequenos pomares, o que atende a um dos aspectos mais importantes da agricultura, o social, permitindo a fixação do homem no campo.

\section{Clima e Solo}

Zayas (1966) recomenda que a gravioleira seja cultivada em altitudes inferiores a $900 \mathrm{~m}$; contudo, Pinto e Silva (1994) observaram excelentes produções obtidas em altitudes de $1.100 \mathrm{~m}$. Por outro lado, Calzavara e Muller (1987) informam que não há restrição ao cultivo das gravioleiras em altitude de até $1.200 \mathrm{~m}$ e precipitações superiores a $1.000 \mathrm{~mm}$ anuais, desde que as chuvas não ocorram no período de frutificação.

\footnotetext{
${ }^{1}$ Palestra Anonáceas - V Congresso Internacional \& Encontro Brasileiro sobre Annonaceae: do gene à exportação (19 a 23 de Agosto de 2013). Botucatu-SP.

${ }^{2}$ Professor-Assistente Doutor, bolsista PQ do CNPq, Universidade Estadual Paulista "Julio de Mesquita Filho" - Unesp - Câmpus de Registro; Rua Nelson Brihi Badur, 430, Vila Tupy - 11900-000 Registro-SP. E-mail: danilorozane@registro.unesp.br ${ }^{3}$ Professor Adjunto, bolsista PQ do CNPq, Unesp - Departamento de Solos e Adubos, Faculdade de Ciências Agrárias e Veterinárias; Via de Acesso Prof. Paulo Donato Castellane, s/n - km 5 - 14870-000, Jaboticabal-SP. E-mail: natale@fcav.unesp.br
} 
Com relação à cherimólia, Morton (1987) relata que, na Colômbia e no Equador, há plantas nativas desenvolvendo- se naturalmente em altitudes entre 1.400 e $2.000 \mathrm{~m}$.

A pinha é cultivada preferencialmente em terras baixas; no entanto, no Brasil, a cultura desenvolve- se adequadamente em altitudes de 900 m (CORDEIRO et al., 2000). Em Cuba, Cañizares e Zayas (1966) já haviam relatado produções de pinha em altitudes de $900 \mathrm{~m}$.

Arango (1975) ressalta que não é recomendada a exploração de anonáceas em regiões sujeitas a temperatura inferiores a $12^{\circ} \mathrm{C}$. A planta deve ser protegida, também, contra ventos fortes, que afetam negativamente a polinização e a frutificação.

Quanto à profundidade e permeabilidade do solo, as anonáceas desenvolvem- se melhor em solos profundos e com boa aeração, o que diminui a ocorrência de podridão radicular. No caso das pinhas, há relatos de morte das plantas após $24 \mathrm{~h}$ de encharcamento do solo (CAÑIZARES ZAYAS, 1966).

\section{Calagem}

Devido à baixa solubilidade dos materiais corretivos da acidez, a incorporação profunda e homogênea do calcário ao solo, antecedendo a implantação das mudas no campo, é prática conhecida e utilizada pelos fruticultores, visto ser a última oportunidade de mobilizar o solo, partindo da premissa de que não é aconselhável revolvê-lo em pomares já implantados, nem tampouco aplicar calcário na cova de plantio, especialmente junto com adubos fosfatados.

Os pomares de frutas são explorações agrícolas de longo prazo, cujas raízes das plantas permanecem praticamente restritas ao mesmo volume de solo por vários anos. Assim, a prévia incorporação homogênea do calcário em profundidade proporcionará ambiente radicular adequado ao eficiente aproveitamento de água e de nutrientes contidos nas camadas corrigidas (DEMATTÊ; VITTI, 1992), afetando positivamente o desenvolvimento e o estado nutricional da frutífera, tendo como consequência o uso racional de fertilizantes e a melhoria da relação benefício/custo, por meio do incremento da produtividade.

Outro aspecto importante da calagem é a longa duração de seu efeito, podendo ser considerado um investimento agrícola, visto que seus benefícios perduram por vários anos. Isso se deve ao efeito residual dos corretivos de acidez, sendo o tempo de duração desse benefício função de vários fatores (NATALE; COUTINHO, 1994), com destaque para o manejo do solo e da cultura. A acidez é reconhecidamente um dos principais fatores da baixa produtividade dos solos brasileiros, sendo, pois, imprescindível a realização da calagem. Porém, apesar da reconhecida necessidade e importância dessa prática agrícola, em especial para as frutíferas (NATALE et al., 2012), não há estudos realizados no Brasil que avaliem os efeitos da calagem em anonáceas, a exemplo do que ocorre para outras frutíferas, como a goiaba (PRADO; NATALE, 2004b; NATALE et al., 2005; NATALE et al., 2007; SOUZA et al., 2009; NATALE et al., 2010), carambola (PRADO et. al., 2007; PRADO; NATALE, 2004a; NATALE et al., 2008; HERNANDES et al., 2010; NATALE et al., 2011), maracujá (PRADO et. al., 2004; PRADO; NATALE, 2005) e citros (SILVA et al., 2007).

Morton (1987) relata que a cultura da cherimólia adapta-se a solos de textura leve a pesada; contudo, recomenda que o cultivo dessa frutífera seja realizado em solos com textura média e fertilidade moderada, cujo $\mathrm{pH}$ varie entre 6,5 e 7,6.

Para o cultivo de anonáceas em condições brasileiras, a faixa de $\mathrm{pH}$ entre 6,0 e 6,6 é a indicada por Pinto e Silva (1994), corroborando informações de Bonaventure (1999), que indica que o $\mathrm{pH}$ do solo deva estar entre 6,2 e 6,5 e, também, de Kavati e Piza Jr. (1997), que indicam a faixa entre 6,5 e 7,5.

Com base nas recomendações de $\mathrm{pH}$ adequado para o cultivo de anonáceas de Morton (1987), Pinto e Silva (1994),Kavati e Piza Jr. (1997) e Bonaventure (1999), pode-se inferir que a calagem deva ser feita para elevar a saturação por bases da camada arável a $80 \%$, e a concentração de magnésio no solo, a um mínimo de $9 \mathrm{mmol} / \mathrm{dm}^{3}$. Contudo, experimentos de campo de longa duração devem ser conduzidos para confirmar e validar esta indicação, a exemplo dos estudos realizados por Natale et al. $(2007,2010)$ para a goiabeira, e,de Natale et al. $(2008,2011)$ para a caramboleira. Essas pesquisas são imprescindíveis, visto haver indicações divergentes sobre a saturação por bases para a cultura da graviola na literatura brasileira (PINTO et al., 2001; VIÉGAS; FRAZÃO, 2004; ANDRADE, 2004).

A calagem é uma prática importante, também, por levar ao solo nutrientes como cálcio e magnésio. Silva et al. (1986) citam que a carência de Ca ocasiona grande redução no desenvolvimento da gravioleira. Morton (1987) relata que um ensaio conduzido em casa de vegetação demonstrou alta sensibilidade da cherimólia à deficiência de cálcio. Em ensaio com gravioleira, Holanda Filho et al. (2006) avaliaram o efeito de doses de nitrogênio e potássio via água de irrigação e concluíram que os nutrientes mais absorvidos pela anonácea foram o $\mathrm{N}$, o K e o Ca. 
A gessagem é, também, uma prática recomendada; porém, somente quando na camada de 0,2-0,4 $\mathrm{m}$ de profundidade são observadas concentrações de $\mathrm{Ca}^{2+}<4 \mathrm{mmol}_{\mathrm{c}} / \mathrm{dm}^{3}$ e/ou de $\mathrm{Al}^{3+}>$ $5 \mathrm{mmol} / \mathrm{dm}^{3}$, associado à saturação por alumínio (m) $>40 \%$ (RAIJ et al., 1997). Andrade (2004) é mais rigoroso em relação a esse aspecto, indicando que a gessagem para gravioleira deve ser realizada quando a saturação por alumínio $(\mathrm{m})>20 \%$ e/ou $\mathrm{Ca}^{2+}<5$ $\mathrm{mmol} / \mathrm{dm}^{3}$ nas camadas de $0,2-0,4 \mathrm{~m}$ ou $0,4-0,6 \mathrm{~m}$ de profundidade. A quantidade de gesso a ser aplicada depende, ainda, da textura do solo, sendo definida pela fórmula: $\mathrm{NG}(\mathrm{kg} / \mathrm{ha})=75 \mathrm{x}$ teor de $\operatorname{argila}(\%)$.

\section{Implantação do Pomar}

Antes da implantação do pomar de anonáceas, a área deve ser previamente limpa, arada, gradeada, além de receber o corretivo de acidez, no mínimo, 90 dias antes do plantio. Entretanto, a coleta e a análise de solo são operações prévias à aração e gradagem, devendo ser realizadas com rigor técnico, amostrando-se, por talhão, 20 pontos (amostras simples) para compor a amostra composta que representa a área e/ou observadas às indicações de Rozane et al. (2011) e Hernandes et al. (2011).

É importante, também, que as mudas para a implantação do pomar sejam provenientes de enxertia e adquiridas de viveiristas idôneos, pois disso depende também o sucesso do empreendimento frutícola.

Na implantação de um pomar de anonáceas, após a calagem, pode-se realizar a abertura das covas com o auxílio de um sulcador, acoplado a um trator, realizando um sulco de $0,4 \mathrm{~m}$ na base superior e de $0,4 \mathrm{~m}$ de profundidade, tendo-se assim uma cova de aproximadamente $\left(0,4 \mathrm{~m}\right.$ x 0,4 $\mathrm{m}$ x 0,4 m) 0,064 $\mathrm{m}^{3}$. Em seguida, realiza-se a demarcação dos locais de plantio das mudas, no espaçamento mais indicado. Cada cova deverá receber $20 \mathrm{~L}$ de composto orgânico curtido à base de esterco bovino; $180 \mathrm{~g}$ de $\mathrm{P}_{2} \mathrm{O}_{5}$ por cova, na forma de superfosfato simples; $2 \mathrm{~g}$ de Zn (Sulfato de Zinco) e $1 \mathrm{~g}$ de B (Ácido Bórico). Salienta-se que não deve ser aplicado calcário na cova de plantio, especialmente junto com fontes de fósforo.

As adubações de cobertura para frutífera, em geral, podem ter início aos 35-40 dias após o transplantio das mudas para o campo. Recomendase aplicar $140 \mathrm{~g}$ de $\mathrm{N}$ e $112 \mathrm{~g}$ de K O por planta, parceladas em quatro vezes, a cada 30 dias, na forma de ureia e cloreto de potássio respectivamente (ROZANE, 2008).

\section{Formação e produção do pomar}

Após o pegamento das mudas e a realização da fertilização de pós-plantio, as adubações de formação e produção do pomar devem ser realizadas com base nos resultados da análise química de solo, na idade da planta ou na produtividade esperada, além do teor de nitrogênio na folha diagnóstica, interpretando-se as Tabelas 1 e 2 .

A análise química do solo deverá ser realizada todos os anos, amostrando-se a projeção da copa das plantas, no final da safra, coletando-se, em cada talhão, 14 e 17 subamostras, respectivamente, nas camadas de $0-0,20 \mathrm{~m}$ e $0,20-0,40 \mathrm{~m}$ ( $\mathrm{f}=20 \%$ ) como recomendado para a cultura da caramboleira (HERNANDES, 2011), uma vez que não há indicação específica para anonáceas.

A análise foliar deve ser realizada todo ano, como recomenda Oliveira (2004); no entanto, quanto ao número de folhas a serem coletadas para diagnose do estado nutricional, sugere-se que sejam amostradas 40 plantas em talhões não irrigados ou 20 plantas em talhões irrigados (ROZANE et al., 2009). Após a amostragem, as folhas devem ser entregues no laboratório, no máximo em 12 h (SOUZA et al., 2010).

A distribuição dos fertilizantes deve ser realizada na projeção da copa das plantas, sem incorporação, a fim de que não haja danos ao sistema radicular superficial, nem tampouco disseminação de pragas e doenças. Independentemente da presença ou da ausência de irrigação no pomar, a adubação fosfatada deve ser realizada em parcela única, tão logo se tenha em mãos o resultado da análise de solo.

A inoculação com fungos micorrízicos arbusculares pode ser uma alternativa interessante para melhorar a eficiência de uso dos adubos fosfatados. Isso foi evidenciado no trabalho de Samarão et al. (2011), que observaram, em mudas de graviola inoculadas com Glomus clarum, Gigaspora margarita, Glomus macrocarpum, Glomus etunicatum e Entrosphopora colombiana, aumento da altura, do diâmetro do caule, maior produção de massa da matéria seca e acúmulo de fósforo nas raízes e na parte aérea, além de maior acúmulo de potássio nas raízes das mudas, comparativamente às plantas não inoculadas.

$\mathrm{Na}$ fase de plena produção do pomar, as adubações com nitrogênio e potássio devem ser divididas em três ou quatro parcelas, a serem aplicadas no início do período chuvoso e distribuídas equidistantes, em toda a volta das plantas, até que os frutos estejam com diâmetro de 3 a $4 \mathrm{~cm}$.

As anonáceas são sensíveis à carência de boro e zinco. Para prevenir tais deficiências, devem-se 
manter os níveis mínimos no solo de $0,4 \mathrm{mg} / \mathrm{dm}^{3}$ de B (extrator água quente) e de 1,0 ou $1,4 \mathrm{mg} / \mathrm{dm}^{3}$ de $\mathrm{Zn}$, respectivamente para os extratores DTPA e Mehlich-1. (RAIJ et al., 1997; GALRÃO, 2004).

Para pomares de gravioleira em produção, Galrão (2004) recomenda a aplicação, por planta, de $2 \mathrm{~g}$ de boro, $3 \mathrm{~g}$ de cobre, $4 \mathrm{~g}$ de manganês e $5 \mathrm{~g}$ de zinco em cobertura. Devido às pequenas quantidades de micronutrientes, sugere-se que as fontes dos fertilizantes sejam solúveis e que a aplicação seja realizada com o auxílio de uma barra de herbicidas acoplada a um trator, a fim de que haja distribuição homogênea dos adubos na projeção da copa das plantas, além de facilitar a aplicação. Outra alternativa de adubação para os micronutrientes é empregar fórmulas NPK contendo boro e/ou zinco em seus grânulos.

A adubação foliar com micronutrientes isoladamente é, via de regra, antieconômica, a menos que conjugada aos defensivos agrícolas. De todo modo, deve ser empregada, sempre, com cautela e rigor técnico.

\section{Diagnose foliar}

Diversos fatores podem ser apontados como responsáveis pela baixa produtividade nas áreas tropicais, destacando-se a limitada capacidade dos solos em atender às exigências nutricionais das plantas, além do manejo inadequado da adubação das culturas. A nutrição e a fertilização são práticas que determinam não apenas a produtividade, mas também a qualidade dos produtos colhidos. Além de interferir no aspecto produtivo e qualitativo, a nutrição mineral afeta o crescimento vegetal, a tolerância a pragas e doenças, bem como o armazenamento das colheitas. Assim, um manejo adequado da nutrição permite racionalizar a aplicação de insumos, como fertilizantes, transformando-se em lucro.

O uso da análise química de plantas para fins de diagnóstico baseia-se na premissa de existirem relações causais entre a taxa de crescimento vegetal e o conteúdo de nutrientes na massa de matéria seca das plantas. As folhas são consideradas o centro das atividades fisiológicas e, em geral, refletem melhor do que qualquer outro órgão o estado nutricional das plantas. Devido à sua sensibilidade, alterações no suprimento de nutrientes têm reflexos nos teores dos elementos nas folhas e estes, por sua vez, refletem no crescimento ou na produtividade das plantas, dentro de certos limites.

O levantamento do estado nutricional das culturas tem sido bastante pesquisado e utilizado, baseado especialmente na interpretação da análise de tecido vegetal, buscando ações para melhorar a produtividade vegetal através da adubação. Entretanto, diversos fatores são apontados como responsáveis pelas variações no conteúdo de nutrientes, com destaque para as condições edafoclimáticas e para os aspectos ligados à cultura, como a idade.

Em anonáceas, especificamente para a gravioleira, Oliveira (2004) recomenda que a amostragem de folhas seja realizada durante o pleno florescimento da cultura, coletando-se, nos quatro pontos cardeais, folhas completamente desenvolvidas, à altura mediana das árvores, em ramos com flores, amostrando-se 25 plantas por talhão.

Lima et al. (2007), estudando a variação nos teores foliares de nutrientes em diferentes partes da copa e dos ramos de graviola, em Pacajus - CE, concluíram que as folhas da parte mediana da copa das árvores, na posição mediana do ramo, refletem adequadamente o estado nutricional das plantas, sendo estas as mais indicadas para amostragem.

Pinto e Silva (1994) recomendam que as folhas coletadas para a diagnose nutricional devem ter de 8 a 9 meses, retiradas de plantas sadias e livres de resíduos de pesticidas. Pinto (2009) complementa que somente devem ser amostradas folhas sadias de plantas não adubadas recentemente, evitando-se os períodos de florescimento e de chuvas intensas.

Na Costa Rica, Laprode (1991) sugere que seja coletado o $3^{\circ}$ ou o $4^{\circ}$ par de folhas a partir do ápice dos ramos, na altura mediana das árvores, nos quatro pontos cardeais.

Batista et al. (2003) e Viégas e Frazão (2004), no Brasil, e Avilan (1975), na Venezuela, cultivando gravioleira em solução nutritiva, observaram os teores de nutrientes que constam na Tabela 3. Oliveira (2004) indica a faixa de teores considerada adequada muito próxima à de Silva e Silva (1986) apresentada na Tabela 3.

Andrade (2004), apesar de recomendar o mesmo padrão de amostragem indicado por Oliveira (2004), apresenta teores diferentes, bem como outras faixas de teores considerados adequados (Tabela 3 ).

Na Tabela 3, estão apresentados, ainda, os teores de nutrientes observados em folhas de Annona crassiflora, conhecida como Araticum, Marolo ou Bruto, constantes do trabalho exploratório de Haridasan (1987).

Diante dos teores de nutrientes apresentados na Tabela 3 para as condições brasileiras, seria indicado que uma primeira aproximação das faixas adequadas de nutrientes para gravioleira fosse a apresentada por Silva e Silva (1986), e uma extrapolação desses teores para as demais anonáceas 
não seria indicada.

Sintomas de deficiência de alguns nutrientes em mudas de gravioleira, em estudo de casa de vegetação, foram descritos por Batista et al. (2003), sendo: a carência de $\mathrm{N}$ provoca nas folhas mais velhas, a partir da região basal, perda gradual da coloração verde para uma tonalidade verde-pálida, distribuindo-se uniformemente no limbo, pecíolo e nervuras. Viégas e Frazão (2004), em estudo semelhante, descrevem plantas com altura reduzida, menor número de folhas, as quais têm coloração amarelada.

A deficiência de P inicia-se nas folhas mais velhas, que se apresentam em relação ao tratamento completo, mais estreitas, com tamanho reduzido, bordos curvados e ápices para baixo. As folhas inferiores, paralelas ao caule, apresentaram coloração verde-clara. Viégas e Frazão (2004) observaram, ainda, redução na altura das plantas, cujas folhas superiores se apresentavam mais estreitas, com tamanho reduzido e bordos curvados, e as folhas inferiores apresentaram-se pendentes ao caule e com coloração verde-clara.

Em relação ao K, a deficiência caracterizouse inicialmente por um esverdeamento intenso da folhagem, com pequena redução no tamanho das folhas novas. Nas folhas mais velhas, a partir do ápice, observou-se clorose marginal, avançando em direção à parte central por entre as nervuras, inicialmente de coloração verde-amarela, evoluíndo para marrom, como consequência da necrose. Com a severidade da deficiência, ocorreram queda das folhas basais e estagnação no crescimento. Viégas e Frazão (2004) observaram redução drástica do crescimento das plantas; nas folhas mais velhas, a partir do ápice, houve clorose marginal, avançando em direção à parte central por entre as nervuras que, no início, apresentavam coloração verde-amarela e, posteriormente, evoluíram para marrom, como consequência da necrose.

As plantas nas quais foi induzida a deficiência de $\mathrm{Ca}$ apresentaram anormalidades nas folhas mais novas, percebendo-se, inicialmente, necrose ao longo da margem superior do ápice da folha, com o restante da folhagem apresentando a cor verde normal. Esta necrose na folha apresentou-se "queimada", de coloração pardo-escura e enrolada sobre si mesma, com bordos recurvados para cima. Com a evolução dos sintomas, houve queda prematura das folhas, e as plantas sofreram redução no crescimento pela paralisação do desenvolvimento apical. Viégas e Frazão (2004) relataram a redução na altura; os sintomas de deficiência apareceram inicialmente nas folhas mais novas, com necrose ao longo da margem superior do ápice da folha; entre as nervuras, a necrose na folha apresentava- se de coloração pardo-escura e enrolada sobre si mesma, com bordos recurvados para cima.

A deficiência de $\mathrm{Mg}$ foi caracterizada pela redução no desenvolvimento da planta; os primeiros sintomas foram observados nas folhas mais velhas, da parte mediana da planta, com um leve amarelecimento ao longo da nervura principal. Entretanto, a nervura principal e as margens laterais das folhas mantiveram-se verdes. À medida que aumentava a intensidade da carência de magnésio, a faixa amarelada tornava-se totalmente alaranjada, ocasionando a abscisão precoce das folhas. Viégas e Frazão (2004) descreveram a deficiência de Mg, cujo sintoma é a clorose ao longo da nervura principal, sendo que a margem das folhas permaneceu verde. Porém, com o agravamento da carência, as folhas ficaram totalmente amareladas, ocasionando queda precoce das mesmas, além de redução na altura das plantas.

Anonáceas com carência de $\mathrm{S}$ apresentaram coloração verde nas folhas novas, em um tom menos claro em relação às folhas do tratamento completo, além de nervuras mais pálidas comparadas ao limbo, tamanho menor, caule mais delgado e crescimento reduzido. Viégas e Frazão (2004) citaram altura reduzida da planta, coloração verde-amarelada das folhas mais novas e nervuras mais claras em relação ao limbo, como sintomas da carência de enxofre.

Quanto à salinidade, Cavalcante et al. (2001) classificaram a gravioleira como moderadamente tolerante a sais, em estudo ralizado para a produção de mudas.

A observação e a identificação de sintomas de deficiências de nutrientes em condições de campo, apesar de rápidas e baratas, requerem muita experiência para sua aplicação, além de induzir a erros quando se emprega esse método; isso é devido aos inúmeros fatores que podem influenciar na sintomatologia apresentada pela planta. Assim, devem-se considerar todas as informações e ferramentas disponíveis (histórico da área, observação de campo, análises de solo, de folhas, de nitrato em pecíolos, de frutos e etc.) para a realização do adequado manejo da adubação e da nutrição das anonáceas.

As pesquisas para estabelecer o estado nutricional dos vegetais levaram ao desenvolvimento de técnicas que evoluíram ao longo do tempo. Dentre os vários métodos de diagnose da nutrição das plantas, podem-se destacar o nível crítico, a faixa de suficiência, o DRIS (Diagnosis and Recommendation Integrated System) e, mais recentemente, o CND 
(Compositional Nutrient Diagnosis) proposto por Parent e Dafir (1992).

O método CND apresenta inúmeras vantagens sobre os demais (PARENT, 2011), pois gera um fator de correção para qualquer nutriente, colocando todos os elementos essenciais em análise (multinutriente), enquanto o DRIS promove um fator de correção simples, para a relação de nutrientes dois a dois. Desse modo, o CND expande o conceito do DRIS de um espaço bidimensional para um multidimensional, além de indicar um padrão nutricional específico para cada frutífera (PARENT, et al., 2013). No Brasil, alguns estudos foram realizados, empregando-se o CND nas culturas da soja (URANO et al., 2006; URANO et al., 2007) e do eucalipto(SILVA et al., 2004).

Para frutíferas, Raghupathi et al. (2002) empregaram a técnica em bananeiras e GarcíaHernández et al. (2009) em Pecã, e para as condições brasileiras, Camacho et al. (2012) para laranjeira Pera e Politi et al. (2013) para a cultura da manga. Rozane et al. (2011), avaliando laranjeiras 'Valência' 'Hamlin' 'Natal' e 'Pera', e empregando as técnicas de meta-análise e CND, concluíram que a laranjeira 'Valência' possui teores de nutrientes distantes das variedades 'Hamlin' 'Natal' e 'Pera', devendo, pois ser diagnosticada separadamente; as laranjeiras 'Hamlin' 'Natal' e 'Pera' podem ser agrupadas para interpretação do diagnóstico nutricional, caso não haja informações específicas para cada genótipo.

Estudos como o realizado por Rozane et al. (2011) demonstram possibilidades reais de agrupamento de espécies de anonáceas. Assim, podem-se utilizar com maior segurança os resultados de alguns estudos já realizados em anonáceas, para frutíferas da mesma espécie que ainda carecem de experimentação. Para tanto, são importantes a organização e a padronização das análises foliares, bem como a mensuração da produção.

TABELA 1- Recomendação de adubação de formação para a gravioleira, de acordo com a idade da planta e a disponibilidade de nutrientes no solo.

\begin{tabular}{cccccccc}
\hline Idade & Nitrogênio & \multicolumn{3}{c}{$\mathrm{P}^{1}\left(\mathrm{mg} / \mathrm{dm}^{3}\right)$} & & \multicolumn{3}{c}{$\mathrm{K}^{2}\left(\mathrm{mg} / \mathrm{dm}^{3}\right)$} \\
& & $<10,0$ & $10,1-15,0$ & $>15,0$ & $<15,0$ & $15,1-40,0$ & $>40,0$ \\
\hline Anos & $\mathrm{N}(\mathrm{g} /$ planta $)$ & $------\mathrm{P}_{2} \mathrm{O}_{5}(\mathrm{~g} /$ planta $)$ & ------ & $-------\mathrm{K}_{2} \mathrm{O}(\mathrm{g} /$ planta $)$-------- \\
1 & 40 & 100 & 60 & 30 & 60 & 40 & 20 \\
2 & 100 & 140 & 100 & 50 & 100 & 60 & 30 \\
3 & 190 & 200 & 140 & 70 & 140 & 90 & 45 \\
4 & 270 & 240 & 160 & 80 & 160 & 110 & 50 \\
\hline
\end{tabular}

Fonte: Andrade (2004); ${ }^{1}$ Extrator Mehlich-1 e teor de argila de 16-35\%; ${ }^{2}$ Extrator Mehlich-1 e teor de argila de $<20 \%$.

TABELA 2- Recomendação de adubação de produção para a gravioleira, de acordo com a produtividade esperada, o teor foliar de $\mathrm{N}$ e a disponibilidade de nutrientes no solo.

\begin{tabular}{cccccccccc}
\hline $\begin{array}{c}\text { Produtividade } \\
\text { esperada }\end{array}$ & \multicolumn{3}{c}{ Teor N na folha $^{1}(\mathrm{~g} / \mathrm{kg})$} & \multicolumn{3}{c}{$\mathrm{P}^{2}\left(\mathrm{mg} / \mathrm{dm}^{3}\right)$} & \multicolumn{3}{c}{$\mathrm{K}^{3}\left(\mathrm{mg} / \mathrm{dm}^{3}\right)$} \\
\hline t/ha & $<18$ & $18-28$ & $>28$ & $<10,0$ & $10,1-15,0$ & $>15,0$ & $<15,0$ & $15,1-40,0$ & $>40,0$ \\
$<5$ & 40 & 30 & 20 & 50 & 30 & 10 & 40 & 30 & 20 \\
$5-10$ & 60 & 50 & 30 & 70 & 50 & 15 & 60 & 40 & 30 \\
$>10$ & 100 & 80 & 50 & 120 & 80 & 20 & 105 & 70 & 50
\end{tabular}

Fonte: Andrade (2004); ${ }^{1}$ Durante o pleno florescimento, coletar, nos quatro pontos cardeais, folhas completamente desenvolvidas na altura mediana da árvore, em ramos com flores; amostrar 25 plantas por talhão (OLIVEIRA, 2004); ${ }^{2}$ Extrator Mehlich-1 e teor de argila de 16-35\%; ${ }^{3}$ Extrator Mehlich-1 e teor de argila de $<20 \%$.

TABELA 3- Teores foliares de nutrientes em anonáceas.

\begin{tabular}{|c|c|c|c|c|c|c|c|c|c|}
\hline Fonte & $\mathrm{N}$ & $\mathrm{P}$ & $\mathrm{K}$ & $\mathrm{Ca}$ & $\mathrm{Mg}$ & $\mathrm{S}$ & $\mathrm{B}$ & $\mathrm{Cu} \mathrm{Fe} \mathrm{Mn}$ & $\mathrm{Zn}$ \\
\hline & --------- & --.-- & ------------ & - $\mathrm{g} / \mathrm{kg}$ & ------------ & ---------- & - ------ & mg/kg ----- & ---- \\
\hline Avilan (1975) & 17,6 & 2,9 & 26,0 & 17,6 & 2,0 & & & & \\
\hline Silva e Silva (1986) & $24,9-28,4$ & $1,4-1,5$ & $26,1-26,4$ & $8,2-16,8$ & $3,6-3,8$ & $1,5-1,7$ & $35-47$ & & \\
\hline Haridasan (1987) & & 0,9 & 6,4 & 8,4 & 1,5 & & & 255104 & 4 \\
\hline Batista et al. (2003) & 14,7 & 0,9 & 12,4 & 14,1 & 3,6 & 5,3 & & & \\
\hline Viégas e Frazão (2004) & 14,3 & $0,8-1,0$ & $11,9-13,1$ & $12,9-15,7$ & $3,2-4,0$ & $3,9-6,0$ & & & \\
\hline Oliveira (2004) & $25-28$ & $1,4-1,5$ & 26,0 & $8-17$ & 4,0 & $1,5-1,7$ & & & \\
\hline Andrade (2004) & $17-28$ & $1,4-9,0$ & $18-26$ & $12-18$ & $2,0-4,0$ & $1,6-2,0$ & $41-49$ & 10100130 & 16 \\
\hline
\end{tabular}




\section{CONCLUSÕES E SUGESTÕES DE PESQUISAS}

Tendo em vista a importância e o potencial de exploração comercial das anonáceas no Brasil e considerando-se a escassa informação científica disponível sobre calagem, adubação e nutrição dessa família de plantas frutíferas, algumas pesquisas têm urgência de serem realizadas em função dos efeitos dos nutrientes sobre a produtividade, a qualidade dos frutos, a pós-colheita, a tolerância a pragas e doenças, etc.Para tanto, será necessária a condução de experimentos de campo, de longa duração, para que os resultados tenham consistência.

1-Determinar a saturação por bases mais adequada às anonáceas, tendo em vista a divergência na literatura disponível;

2-Determinar a folha diagnóstica, bem como a época de coleta e o número de plantas a serem amostradas;

3-Determinar doses, épocas, modos de aplicação e fontes de nutrientes para a produção de mudas;

4-Determinar doses, épocas, modos de aplicação e fontes de nutrientes para pomares de anonáceas em formação e produção;

5-Determinar a distribuição do sistema radicular das plantas no campo, a fim de melhorar a aplicação do calcário e dos fertilizantes;

5-Realizar o levantamento do estado nutricional de anonáceas em pomares comerciais de alta produtividade, empregando ferramentas modernas de interpretação como a meta-análise e o CND, com o objetivo de estabelecer o equilíbrio nutricional dessas frutíferas.

\section{REFERÊNCIAS}

ANDRADE, L. R. M. de. Corretivos e fertilizantes para culturas perenes e semiperenes. In: SOUSA, D. M. G. de; LOBATO, E. (Ed.). Cerrado: correção do solo e adubação. Brasília: Embrapa Informação Tecnológica, 2004. p. 317-366.

ARANGO, F.T. La guanábana (Annona muricata L.) Revista Esso Agrícola, v. 21, n.2, p.5 - 10, 1975.

AVILAN, L. R. Efecto de la omisión de los macronutrientes en el desarrollo y composición química de la guanábana (Annona muricata L.) cultivada en soluciones nutritivas. Agronomía Tropical, Maracay, v.25, n.1, p.73-79, 1975.
BATISTA, M. M. F.; VIÉGAS, I. de J. M.; FRAZÃO, D. A. C.; THOMAZ, M. A. A.; SILVA, R. de C. da. Efeito da omissão de macronutrientes no crescimento, nos sintomas de deficiências nutricionais e na composição mineral em gravioleiras (Annona muricata). Revista Brasileira de Fruticultura, Jaboticabal, v.25, p. 315-318, 2003.

BONAVENTURE, L. A cultura da cherimóia e de seu híbrido a atemóia. São Paulo: Nobel, 1999. $182 p$.

CAMACHO, M. A.; SILVEIRA, M. V.; CAMARGO, R. A.; NATALE, W. Faixas normais de nutrientes pelos métodos ChM, DRIS e CND e nível crítico pelo método de distribuição normal reduzida para laranjeira-pera. Revista Brasileira de Ciência do Solo, Viçosa, MG, v.36, p.193-200, 2012.

CALZAVARA，B.B.G.; MÜLLER，C.H Fruticultura tropical: a gravioleira. Belém: Embrapa- CPATU, 1987. 36p. (Embrapa-CPATU. Documentos, 47).

CAÑIZARES ZAYAS, J. La polinización artificial de las flores en algunas especies de plantas anonaceas. Santiago de las Vegas: Centro Nacional de Experimentación y Extensión Agricola, 1966. 16p.

CAVALCANTE, L. F.; CARVALHO, S. S. de; LIMA, E. M. de; FEITOSA FILHO, J. C.; SILVA, D. A. da. Desenvolvimento inicial da gravioleira sob fontes e níveis de salinidade da água. Revista Brasileira de Fruticultura, Jaboticabal, v.23, p. 455-459, 2001.

CORDEIRO, M. C. R.; PINTO, A. C. de Q.; RAMOS, V. H. V. O cultivo da pinha, fruta-doconde ou ata no Brasil. Planaltina: EMBRAPA Cerrados, 2000. 52p. (Circular Técnica, 9).

DEMATTÊ, J. L. I.; VITTI, G. C. Alguns aspectos relacionados ao manejo de solos para citros. In: SIMPÓSIO INTERNACIONAL DE CITROS FISIOlOGiA, 2., 1992, Bebedouro. Anais... Campinas: Fundação Cargill, 1992. p.67-99.

DONADIO, L. C. Situação atual e perspectivas das anonáceas. In: SÃO JOSÉ, A. R.; VILAS BOAS, I.; MARAIS, O. M.; REBOUÇAS, T. N. H. (Ed.). Anonáceas: produção e mercado (pinha, graviola, atemóia e cherimólia). Vitória da Conquista: Universidade Estadual do Sudoeste da Bahia, 1997. p.1-4. 
GALRÃO, E. Z. Micronutrientes. In: SOUSA, D. M. G. de; LOBATO, E. (Ed.). Cerrado: correção do solo e adubação. Brasília: Embrapa Informação Tecnológica, 2004. p.185-226.

GARCÍA-HERNÁNDEZ，J. L.; ORONACASTILLO, I.; GONZÁLEZ-CERVANTES, G.; VALDEZ-CEPEDA, R. D.; MURILLOAMADOR, B.; TROYO-DIÉGUEZ, E.; FORTISHERNÁNDEZ, M.; SEGURA-CASTRUITA, M. A. Interacciones nutrimentales y normas de diagnósitico de nutrimento compuesto en nogal pecanero (Carya illinoensis). Revista Chapingo, Chapingo, v. 15, p. 141-147, 2009.

HARIDASAN, M. Distribution and mineral nutrition of aluminium accumulating species in different plant communities of the cerrado region of central Brazil. Brasília: UNB, 1987.

HERNANDES, A.; NATALE, W.; PRADO, R. M.; ROZANE, D. E.; ROMUALDO, L. M. ; SOUZA, H. A. . Calagem no crescimento e desenvolvimento da caramboleira. Revista Brasileira de Ciências Agrárias, Recife, v.5, n.2, p.170-276, 2010.

HERNANDES, A.; ROZANE, D. E.; SOUZA, H. A. de; ROMUALDO, L. M.; NATALE, W. Amostragem para diagnose do estado nutricional e avaliação da fertilidade do solo de caramboleiras. Bragantia, Campinas, v.70, p.657-663, 2011.

HERNANDES, A.; ROZANE, D. E.; SOUZA, H. A.; ROMUALDO, L. M.; NATALE. Amostragem para diagnose do estado nutricional e avaliação da fertilidade do solo em caramboleiras. Bragantia, Campinas, v. 70, n. 3, p.657-663, 2011.

HOLANDA FILHO, R. S. F.; SOUSA, V. F.; AZZEVEDO, B. M.; ALCÂNTARA, R. M. C. M.; RIBEIRO, V. Q.; ELOI, W. M. Efeitos da fertirrigação de $\mathrm{N}$ e $\mathrm{K}_{2} \mathrm{O}$ na absorção de macronutrientes pela gravioleira. Revista Brasileira de Engenharia Agrícola e Ambiental, Campina Grande, v. 10, p.43-49, 2006.

KAVATI, R.; PIZA JR, C. de T. Formação e manejo do pomar de fruta-do-conde, atemóia e cherimóia. In: SÃO JOSÉ, A. R.; VILAS BOAS, I.; MARAIS, O. M.; REBOUÇAS, T. N. H. (Ed.). Anonáceas: produção e mercado (pinha, graviola, atemóia e cherimólia). Vitória da conquista: Universidade Estadual do Sudoeste da Bahia, 1997. p.75-83.
LAPRODE, S.C. Variación estacional de nutrimentos foliares em guanabana (Annona muricata L.). Corbana, Costa Rica, v. 15, p.6-10. 1991.

LIMA, R. de L. S. de; FERREIRA, G. B.; WEBER, O. B.; CAZETTA, J. O. Diagnose foliar da gravioleira (Annona muricata L.): efeito da posição de ramos e folhas. Ciência e Agrotecnologia, Lavras, v.31, p.1320-1325, 2007.

MORTON, J. Cherimoya. In: MORTON, J.F. (Ed.). Fruits of warm climates. Miami: Florida Flair Books, 1987. p.65-69.

NATALE, W.; COUTINHO, L M. Avaliação da deficiência agronômica de frações granulométricas de um calcário dolomítico. Revista Brasileira de Ciência do Solo, Viçosa, MG, v. 18, n.1, p. 55-62, 1994.

NATALE, W.; PRADO, R. de M.; ROMUALDO, L. M.; ROZANE, D. E. Efeitos da calagem na fertilidade do solo e na nutrição e produtividade da goiabeira. Revista Brasileira de Ciência do Solo, Viçosa, MG, v.31, p.1475-1484, 2007.

NATALE, W.; PRADO, R. de M.; ROZANE, D. E.; ROMUALDO, L. M.; SOUZA, H. A. de; HERNANDES, A. Resposta da caramboleira a calagem. Revista Brasileira de Fruticultura, Jaboticabal, v.30, p.1136-1145, 2008.

NATALE, W.; PRADO, R. M.; MÔRO, F. V. Alterações anatômicas induzidas pelo cálcio na parede celular de frutos de goiabeira. Pesquisa Agropecuária Brasileira, Brasília, v. 40, n.12, p. 1239-1242, 2005.

NATALE, W.; ROZANE, D. E.; PARENT L. E.; PARENT, S.E. Acidez do solo e calagem em pomares de frutíferas tropicais. Revista Brasileira de Fruticultura, Brasília, v. 34, p. 1294-1306, 2012.

NATALE, W.; ROZANE, D. E.; PRADO, R. de M.; ROMUALDO, L. M.; SOUZA, H. A. de; HERNANDES, A. Viabilidade econômica do uso do calcário na implantação de pomar de goiabeiras. Ciência Agrotecnologia, Lavras, v. 34, p. 708-713, 2010. 
NATALE, W.; ROZANE, D. E.; PRADO, R. de M.; ROMUALDO, L. M.; SOUZA, H. A. de; HERNANDES, A. Dose econômica de calcário na produtividade de caramboleiras. Revista Brasileira de Fruticultura, Jaboticabal, v. 33, p. 1294-1299, 2011.

OLIVEIRA, S. A. de. Análise foliar. In: SOUSA, D. M. G. de; LOBATO, E. (Ed.). Cerrado: correção do solo e adubação. Brasília: Embrapa Informação Tecnologia, 2004. p.245-282.

PARENT, L. É. Diagnosis of the nutrient compositional space of fruit crops. Revista Brasileira de Fruticultura, Jaboticabal, v.33, n.1, p. 321-334, 2011.

PARENT, L. E.; DAFIR, M. A theorical concept of compositional nutriente diagnosis. Journal of the American Society for Horticultural Science, Alexandria, v.117, p.239-242, 1992.

PARENT, S. E.; PARENT, L. E.; EGOZCUE, J. J.; ROZANE, D. E.; HERNANDES, A.; LAPOINTE, L.; HÉBERT-GENTILE, V.; NAESS, K.; MARCHAND, S.; LAFOND, J.; MATTOS, D. ; BARLOW, P.; NATALE, W. The plant ionome revisited by the nutrient balance concept. Frontiers in Plant Science, New Haven, v. 4, p. 1-10, 2013.

PINTO, A. C. DE Q. GRAVIOLEIRA. IN: CRISÓSTOMO, L. A.; NAUMOV, A. (Org.). Frutíferas tropicais do Brasil: adubando para alta produtividade e qualidade. Fortaleza: International Potash Institute/Embrapa Agroindústria Tropical, 2009. v.1, p.206-222.

PINTO, A. C. de Q.; SILVA, E. M. da; RAMOS; V. H. V.; RODRIGUES, A. A. Tratos Culturais. In: OLIVEIRA, M.A.S. (Ed.). Graviola, produção. Brasília: Embrapa Informação Tecnológica, 2001. p.26-33.

PINTO, A. C. de Q.; SILVA, E. M. Graviola para exportação, aspectos técnicos da produção. Brasília: Embrapa, 1994.

POLITI, L. S.; FLORES, R. A.; SILVA, J. A. S.; WADT, P. G. S.; PINTO, P. A. C.; PRADO, R. $\mathrm{M}$. Estado nutricional de mangueiras determinado pelos métodos DRIS e CND. Revista Brasileira de Engenharia Agrícola Ambiental, Campina Grande, v.17, n. 1, p.11-18, 2013.
PRADO, R. M.; NATALE, W. A calagem na nutrição e no desenvolvimento do sistema radical da caramboleira. Revista de Ciências Agroveterinárias, Lages, v. 3, n.1, p. 3-8, 2004 a.

PRADO, R. M.; NATALE, W. Calagem na nutrição de cálcio e no desenvolvimento do sistema radicular da goiabeira. Pesquisa Agropecuária Brasileira, Brasília, v. 39, n.10, p. 1007-1012, 2004 b.

PRADO, R. M.; NATALE, W. Efeito da aplicação de silicato de cálcio no crescimento, no estado nutricional e na produção de matéria seca de mudas de maracujazeiro. Revista Brasileira de Engenharia Agrícola e Ambiental, Campina Grande, v. 9, n.2, p. $185-190,2005$

PRADO, R. M.; NATALE, W.; CORRÊA, M. C. M.; BRAGHIROLLI, L. F. Efeitos da aplicação de calcário no desenvolvimento, no estado nutricional e na produção de matéria seca de mudas de maracujazeiro. Revista Brasileira de Fruticultura, Jaboticabal, v. 26, n.1, p. 145-149, 2004.

PRADO, R. M.; NATALE, W.; ROZANE, D. E. SoilLiming Effects on the Development and Nutritional Status of the Carambola Tree and Its Fruit-Yielding Capacity. Communications in Soil Science and Plant Analysis, New York, v. 38, p. 493-511, 2007.

RAGHUPATHI, H. B.; REDDY, B. M. C.; SRINIVAS, $\mathrm{K}$. Multivariate diagnosis of nutrient imbalance in banana. Communications in Soil Science and Plant Analysis, New York, v. 33, p.2131-2143, 2002.

RAIJ, B. van; QUAGGIO, J. A.; CANTARELLA, H.; ABREU, C. A. de. Interpretação de resultados de análise de amostras de subsolo. In: RAIJ, B. van; CANTARELLA, H.; QUAGGIO, J. A.; FURLANI, A. M. C. (Ed.). Recomendação de adubação e calagem para o Estado de São Paulo. Campinas: IAC, 1997. p.1-13. (Boletim Técnico, 100).

ROZANE, D. E. Crescimento e acúmulo de nutrientes em caramboleiras nas fases de hipobioto, muda e plantas em formação. 2008. 116 f. Tese (Doutorado) - Faculdade de Ciências Agrárias e Veterinárias, Universidade Estadual Paulista, Jaboticabal, 2008. 
ROZANE, D. E.; MATTOS JÚNIOR, D.; S. E. PARENT, NATALE, W.; PARENT, L. E. Compositional meta-analysis of citrus varieties in the state of São Paulo, Brazil. In: INTERNATIONAL WOKSHOP ON COMPOSITIONAL DATA ANALYSIS, 4., 2011. Girona. Proceedings...11p.

ROZANE, D. E.; NATALE, W.; PRADO, R. de M.; BARBOSA, J. C. Tamanho da amostra foliar para avaliação do estado nutricional de goiabeiras com e sem irrigação. Revista Brasileira de Engenharia Agrícola e Ambiental, Campo Grande, v.13, p.233239, 2009.

ROZANE,D.E.; ROMUALDO,L.M.; CENTURION, J. F.; BARBOSA, J. C. Dimensionamento do número de amostras para avaliação da fertilidade do solo. Semina: Ciências Agrárias, Londrina, v. 32, n. 1, p. 109-116, 2011.

SAMARÃO, S. S.; RODRIGUES, L. A.; MARTINS, M. A.; MANHÃES, T. N.; ALVIM, L. A. da M. Desempenho de mudas de gravioleira inoculadas com fungos micorrízicos arbusculares em solo nãoesterilizado, com diferentes doses de fósforo. Acta Scientiarum. Agronomy, Maringá, v.33, p.81-88, 2011.

SILVA, A. Q. da; SILVA, H. Nutrição e adubação em anonáceas. In: SÃO JOSÉ, A. R.; VILAS BOAS, I.; MARAIS, O. M.; REBOUÇAS, T. N. H. (Ed.). Anonáceas: produção e mercado (pinha, graviola, atemóia e cherimólia). Vitória da Conquista: Universidade Estadual do Sudoeste da Bahia, 1997. p.118-137.

SILVA, G. G. C. ; NEVES, J. C. L.; ALVAREZ V., V. H.; LEITE, F. P. Nutritional diagnosis for eucalypt by DRIS, M-DRIS, and CND. Scientia Agricola, Piracicaba, v.61, p.507-515, 2004.

SILVA, H.; SILVA, A. Q. da. Nutrição mineral e adubação de anonas. In: HAGG, H. P. ed., Nutrição mineral e adubação de fruteiras tropicais. Campinas: Fundação Cargill, 1986. p.285-342.

SILVA, H.; SILVA, A. Q. DA; CAVALCANTE, F. B.; MALAVOLTA, E. Nutrição mineral da graviola (Anonna muricata L). II. Teores de macronutrientes e de boro. In: CONGRESSO BRASILEIRO DE FRUTICUlTURA, 8., 1986. Brasília. Anais... Brasília: SBF, 1986. p.303-307.
SILVA, M. A. C.; NATALE, W. ; PRADO, R. M.; CORRÊA, M. C. M.; STUCHI, E. S.; ANDRIOLI, I. Aplicação superficial de calcário em pomar de laranjeira Pêra em produção. Revista Brasileira de Fruticultura, Jaboticabal, v. 29, p. 606-612, 2007.

SOUZA, H. A.; NATALE, W.; PRADO, R. M.; ROZANE, D.E.; ROMUALDO, LM; HERNANDES, A. Efeito da calagem sobre o crescimento de goiabeiras. Revista Ceres, Viçosa, MG, v. 56, p. 336-341, 2009.

SOUZA, H. A.; ROZANE, D. E.; HERNANDES, A.; ROMUALDO, L. M.; NATALE, W. Variação no teor de macronutrientes de folhas de goiabeira, em função do tipo e tempo de armazenamento. Biotemas, Florianópolis, v.23, p. 25-30, 2010.

SOUZA, V. C.; LORENZI, H. Botânica sistemática: guia ilustrado para identificação das famílias de Angiospermas da flora brasileira, baseado em APG II. Nova Odessa: Instituto Plantarum, 2005. 640p.

URANO, E.O.M.; KURIHARA, C.H.; MAEDA, S.; VITORINO, A.C.T.; GONÇALVES, M.C.; MARCHETTI, M.E. Avaliação do estado nutricional da soja. Pesquisa Agropecuária Brasileira, Brasília, v.41, p. 1421-1428, 2006.

URANO, E.O.M.; KURIHARA, C.H.; MAEDA, S.; VITORINO, A.C.T.; GONÇALVES, M.C.; MARCHETTI, M.E. Determinação de teores ótimos de nutrientes em soja pelos métodos chance matemática, sistema integrado de diagnose e recomendação e diagnose da composição nutricional. Revista Brasileira de Ciência do Solo, Viçosa, MG, v.31, p.63-72, 2007.

VIÉGAS, I. de J. M.; FRAZÃO, D. A. C. Graviola: nutrição, calagem e adubação. Belém: EMBRAPA Amazônia Oriental, 2004. 6p. (Circular Técnica, 36).

ZAYAS, J. C. Las frutas anonáceas. Havana: Ediciones Fruticuba, 1966. 